\title{
6. Lobbying or politics? Political claims making in IP conflicts
}

\section{Sebastian Haunss and Lars Kohlmorgen ${ }^{1}$}

\section{INTRODUCTION}

In the official declaration of the 2007 G8 summit in Heiligendamm, Germany, the heads of government of the eight most powerful industrialized countries gave the "protection of intellectual property rights" top priority. In fact, IP protection was mentioned in their final statement even ahead of climate change, as a political issue of crucial importance, preceded only by global economic growth, the stability of financial markets, and the freedom of investment. The statement stressed that "Innovation is one of the crucial drivers of economic growth in our countries.... The protection of IPRs is of core interest for consumers in all countries, particularly in developing countries" (G8 2007, 2). This prominent placement reflects the growing importance of the politics of intellectual property, which has changed over the last 15 years from a field of technical expertise to an increasingly contentious global political issue.

How did the protection of intellectual property (IP) become such a high-level issue? And how has the idea that strong intellectual property regimes should be a central component of any global trade regime become the dominant view?

Susan Sell (2003) shows in her study of the history of the Agreement on Trade-Related Aspects of Intellectual Property Rights (TRIPS) how, during the Uruguay round of global trade talks, a small group of transnational corporations successfully got IP protection on the agenda and subsequently managed to codify their vision of a strong IP protection regime, in the form of the TRIPS agreement, with relatively little contestation (Sell 2003; Drahos and Braithwaite 2003). The political process that yielded TRIPS is an excellent example of a power game in which resourcerich private actors are able to get their way, with support from the powerful governments of industrialized countries. In this case, they managed to successfully install a global IP regime that requires all WTO member countries to adopt strong national systems of IP protection. Developing 
countries that initially tried to resist the tightened IP regime were silenced through the US initiating "Section 301 actions", that is, bilateral trade sanctions (Meier 2005, 506).

Sell's study also shows that the success of the lobbying that led to the TRIPS agreement cannot be explained merely in terms of power dynamics. Many of the same resourceful and powerful actors were not that successful a few years later during the negotiations of the new WIPO copyright treaties, which consequently, in their current version, exhibit a much more balanced approach between authors' rights and the public's interest in having access to information (Sell 2003, 26). As Sell shows, in this second set of negotiations a well-organized group of opponents successfully framed IP as an issue of "fair use" to counter the dominant frame of IP as a trade issue. These findings suggest that a strategy focused on achieving discursive hegemony was at least partially able to compensate for weakness in terms of economic power.

The TRIPS story was not just a story of financial resources and economic power. As Sell argues, it "is difficult to overestimate" the influence of Jacques Gorlin, advisor to the US Advisory Committee for Trade Negotiations (ACTN) and the private Intellectual Property Committee (IPC) (Sell 2003, 49). Gorlin's achievement was to develop a coherent argumentation framing intellectual property rights as a (free) trade issue an inherently contradictory task, since intellectual property rights are by definition monopolies granted by the State for a designated period of time, and therefore intrinsically contradict the idea of free market competition (Gorlin 1985). Obviously, constructing the right frame is important not only for weak actors but also for the powerful players in the field. Indeed, the above cited G8 policy statement can be read as an attempt to re-frame IP as an issue of consumer interests in the Global South - a quite surprising interpretation that clearly reflects the growing number of challenges to the TRIPS framing of IP as a trade issue.

The importance of framing processes as discursive interventions that influence policy outcomes has been overlooked in much of the interest groups literature, which focuses mainly on the resources actors have at their disposal (Bouwen 2002; Greenwood 1997; Richardson 2000). On the other hand, research on social movements has long acknowledged that, aside from resources and political opportunities, the construction of collective action frames is an important factor in its own right for explaining movement success or failure (Snow and Benford 1992; Snow et al. 1986; Gamson et al. 1982).

Granting the importance of framing processes, then, the question remains: which frames can successfully influence IP policies and under what conditions? Sell's example of the WIPO copyright treaties suggests 
that actors need to construct a convincing counter-frame that offers an alternative interpretative frame. The conflict about IP issues and global health policies also follows this pattern. Here the construction of a counter-frame that pitted IP protection for pharmaceuticals against public health was a successful strategy for those actors that wanted to prioritize the fight against HIV/Aids (Hein 2007; Hein and Kohlmorgen 2008).

However, the literature on framing is only partially helpful here. An impressive number of case studies (see Benford and Snow 2000; Snow 2004 for an overview) have detailed framing processes in different social movements and have identified the complex discursive strategies necessary to construct potent collective action frames. Most notably several studies have pointed out that, to be successful, collective actors need to construct a coherent master frame that has the potential to ideologically integrate a heterogeneous set of actors (Gerhards and Rucht 1992, 573; Snow and Benford 1992, 138). A number of frame typologies have been developed, but so far none of them has been able to explain which framing strategies might be more successful than others.

This chapter starts from the general assumption that framing processes do indeed matter, and examines their role in two recent conflicts in the European Union over two EU directives in the field of IP policies. Based on our analysis of these cases, we argue that the construction of a coherent master frame was a precondition for successful mobilization, especially for resource-poor actors. Our findings challenge the notion that the success of oppositional actors always depends on their ability to construct a strong counter-frame. Instead, we argue that displacement strategies, which attempt to re-frame an already existing hegemonic frame and give it a new meaning, may often be just as fruitful, especially where IP protection cannot easily be portrayed as a threat to some common normative value.

\section{CONFLICTS ABOUT THE EU DIRECTIVES ON SOFTWARE PATENTS AND IP ENFORCEMENT}

The two directives we will analyze have played a central role in shaping the regulatory framework for intellectual property rights in the EU over the last decade. Both directives were introduced and decided upon between 1997 and 2005. Both were carried out under the "co-decision" procedure, in which the European Parliament and the European Council must reach agreement on the issue. They were drafted in the same Directorate General in the Commission (DG Internal Market), and in both cases they faced 
opposition from stakeholders, who tried to influence the decision-making process in their favor. ${ }^{2}$

The "Directive on the Enforcement of Intellectual Property Rights" (IPRED 1, or the IP Enforcement Directive) was intended to strengthen and harmonize the enforcement of intellectual property rights, including copyrights, trademarks, and patents, in the EU member states. It requires all member states to apply "penalties which must be effective, proportionate and deterrent" (COM 2003, 19) against counterfeiting and piracy. The directive gives rights holders more possibilities to bring civil suit against counterfeiters and other violators. Rights holders, for example, may call on judicial authorities to issue an interlocutory injunction preventing further infringement of intellectual property rights or to demand destruction of counterfeited goods.

The second directive, the "Directive on the Patentability of Computer Implemented Inventions" was drafted by the Commission to introduce patents on inventions "implemented on a computer or similar apparatus which is realised by a computer program" (COM 2002, 13). Whether this definition would include "software as such", which is explicitly exempted from patentability under the European Patent Convention, was a highly contested question in the conflict around this directive. In any case, the opponents of the directive successfully framed it as the "Software Patents Directive" (SWPat), while only the core supporters referred to it as the CII Directive. ${ }^{3}$

In both cases the Commission received strong support from industry lobbying groups and business associations, which represented a number of powerful key players in the respective fields. However, business interests did not unanimously support the Commission's proposals in either case. Major firms from the European telecommunications industry opposed the Enforcement Directive, and a large number of mostly small and medium enterprises (SMEs) opposed the Software Patents Directive. Civil society and consumer interest groups mobilized against the directives in both cases. Members of the European Parliament (MEPs), national politicians, and scientific experts can be found in both the proponents' and opponents' camps in both conflicts.

Despite the similarities in the two decision-making processes, there were significant differences in the trajectories and intensity of the conflicts. While there was heated debate over the pros and cons of software patents ${ }^{4}$ - an issue that initially seemed much less controversial - the legislative process in the case of the IP Enforcement Directive went relatively smoothly and the directive was adopted without much disturbance, even though one would expect more conflict here, since the directive touches on issues like file-sharing that have received substantially more public attention than the 
arcane subject of software patents. We argue that the contrasting trajectories and outcomes in these two conflicts can be explained by examining their framing processes.

\section{METHODOLOGY}

To collect data about the actors involved in the two IP conflicts and about their positions and frames, we used the methodological framework of political claims analysis developed by Koopmans and his collaborators (Koopmans and Statham 1999). The principal idea in this approach is to analyze the claims of all of the actors involved in a political conflict - as opposed to just the challengers - expressed in their forms of action and interaction and in their collective action frames. The idea here is that, since collective action that goes beyond lobbying depends heavily on establishing a presence in the public sphere, only claims that are reported in the media are of interest, because they are the only claims that have a chance of influencing the decision-making process. Political claims analysis combines the empirical power of traditional protest event analysis with the analytical power of a frame analysis at the discursive level, and tries to map the claims of all actors, not just those of the challengers, within a given policy field. Drawing on Koopmans and Statham's (1999) definition, we conceptualize claims as demands, proposals, criticisms, decisions, and so on made by actors active in the respective field of conflict in the form of statements or collective mobilizations. A frame is understood as an "interpretive schemata that simplifies and condenses the 'world out there' by selectively punctuating and encoding objects, situations, events, experiences, and sequences of actions within one's present or past environment" (Snow and Benford 1992, 137).

For our two cases we analyzed data from quality newspapers in four countries: Germany, France, the UK and Poland. In general, we included France, Germany, and the UK because of their political and economic importance in Europe. Another reason for including the UK is that it has the most liberal patent practices with respect to software patents. It was also important to include France, because in both conflicts the rapporteurs of the EP were French nationals, and because France was one of the most vocal critics of software patents. Germany was an essential candidate because the most important oppositional actor in the software patents conflict, the Foundation for a Free Information Structure (FFII), had its origins in Germany, and because it represents a country with a comparatively strict practice with regard to the granting of software patents. Finally, Poland was selected because of its important role in the software 
patents conflict, where it was the most vocal of the newly acceded East European countries in criticizing the Software Patents Directive.

For all the countries we analyzed all newspaper articles, published between January 1997 and July 2005 in selected national quality newspapers, that mentioned either or both of the conflicts or centrally dealt with the subject of software patents or the general issue of IP enforcement, and that were available in the full text collection of LexisNexis for the whole period. Lastly, articles were only coded if they contained a claim. They were not included in the database if they only contained some information about the respective issues or if no attributions to specific actors were made. Overall a total of 188 articles (G: 75 , UK: $37, F: 45$, PL: 31) were coded according to a previously developed code book (Haunss and Kohlmorgen 2008a), which had been adapted from the code book used in the EUROPUB project (Koopmans 2002). A total of 324 claims were reported in the articles; 277 related to the Software Patents Directive and 47 to the IP Enforcement Directive.

\section{RESULTS}

The claims making in the two conflicts differed significantly, both in content and in scope. Figure 6.1 shows that in both cases the overall pattern of claims making expressed in the newspaper articles closely reflects important steps in the decision-making process, with peaks in the number of claims reported corresponding to the publication of the directive proposals, their readings in the parliament, and the meetings of the Council.

A comparison of the timelines also immediately reveals a number of important differences. The most striking, as already mentioned, is the contrasting levels of intensity in the two conflicts, with 277 claims in the software patents conflict but only 47 in the conflict over the Enforcement Directive. A second set of differences relates to the timing and developmental patterns of public claims making. There were several waves of intense claims making in the software patents conflict, peaking at the time of the second reading of the directive in the European Parliament, whereas in the other conflict only one wave of claims making made it into the news, at the very end of the conflict. With few exceptions, the contention was publicly visible in the Enforcement Directive conflict only between September 2003 and March 2004, in the six months before the first and only reading in the EP. Moreover, it is only in this last stage that there was relatively balanced reporting of the claims of both supporters and opponents of the directive. The first claims were made exclusively by the 

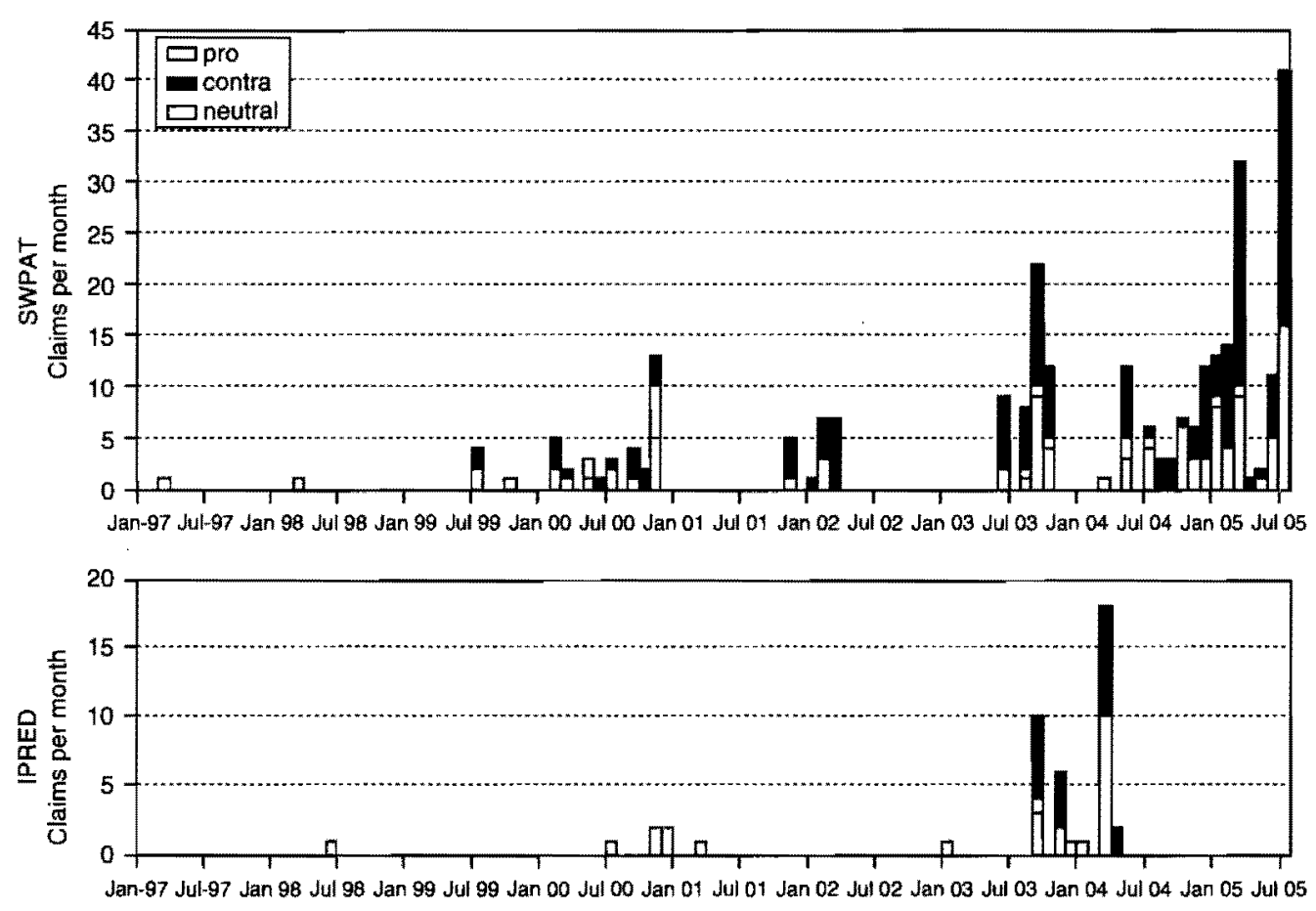

Figure 6.1 Timeline of claims making in both conflicts

European Commission, who announced the publication of the proposal for the directive several times. It is also significant that during the whole conflict the proponents' claims were reported significantly more often than those of the directive's opponents ( 51.1 per cent of the total claims versus 42.6 per cent, with the remaining 6.3 per cent being neutral).

On the other hand, in the software patents conflict, opponents of the directive entered the stage much earlier. The first claims against the proposed directive were reported in the newspapers as early as July 1999, and throughout the conflict the directive's opponents remained highly visible, with 58.1 per cent of the total reported claims being made by opponents and only 35.4 per cent by supporters of the directive. The remaining 6.5 per cent of the claims were either neutral or ambivalent.

Regardless of timing, the successful group of actors in both cases were those whose claims received greater exposure in the media. The opponents of software patents successfully defeated the directive, while the proponents of the Enforcement Directive succeeded in getting it adopted. As the timelines clearly show, the software patents conflict took place to a large degree in the public sphere and therefore was a public political conflict, whereas the conflict over the Enforcement Directive could be better characterized as a struggle between lobbyists, which only at the very end became a publicly visible political conflict. 
To get a more detailed picture of the conflicts beyond these structural characteristics we analyzed three additional aspects of the claims-making process, to which we now turn: which actors were present in the conflict; which forms of action the opposing parties chose to utilize; and how they framed their claims.

\subsection{Actors and Actions}

The most visible actors in both IP conflicts, in terms of newspaper coverage, were parliamentarians and political parties from the European Parliament. They were responsible for 18.8 per cent of the claims in the software patent conflict and for almost one-third (29.2 per cent) of the claims in the conflict about the Enforcement Directive. In contrast, the Commission played a much smaller role, garnering only 5.6 per cent and 8.3 per cent of the coverage, respectively.

As expected, the greater intensity of the software patents conflict brought more actors into the conflict. Two groups are especially noteworthy here: small and medium-sized enterprises (SMEs) and lawyers. The significant number of lawyers involved in the conflict is an expression of

Table 6.1 Actors present in the software patents conflict

\begin{tabular}{lccrrr}
\hline Actor & \multicolumn{2}{c}{ Reported Claims } & Pro & \multirow{2}{*}{ Con } & \multirow{2}{*}{ Neutral } \\
\cline { 2 - 4 } & Percentage & Number & & & \\
\hline European Parliament & 18.8 & 54 & 12 & 41 & 1 \\
Civil society organizations & 11.8 & 34 & 2 & 32 & 0 \\
Small and medium-sized & 11.8 & 34 & 0 & 34 & 0 \\
enterprises (SMEs) & 10.1 & 29 & 21 & 5 & 3 \\
Large corporations & 10.1 & 29 & 19 & 8 & 2 \\
Business associations & 8.0 & 23 & 8 & 11 & 4 \\
National governments & 6.6 & 19 & 11 & 4 & 4 \\
Lawyers & 5.6 & 16 & 1 & 14 & 1 \\
National politicians & 5.6 & 16 & 16 & 0 & 0 \\
European Commission & 4.5 & 13 & 1 & 9 & 3 \\
Scientists & 2.8 & 8 & 1 & 7 & 0 \\
Media and journalists & 1.7 & 5 & 5 & 0 & 0 \\
European Council & 1.4 & 4 & 1 & 0 & 3 \\
Patent offices & 1.0 & 3 & 0 & 3 & 0 \\
National parliaments & $100^{*}$ & 287 & 98 & 168 & 21 \\
Sum & & & & & \\
\hline
\end{tabular}

Note: * Error due to rounding. 


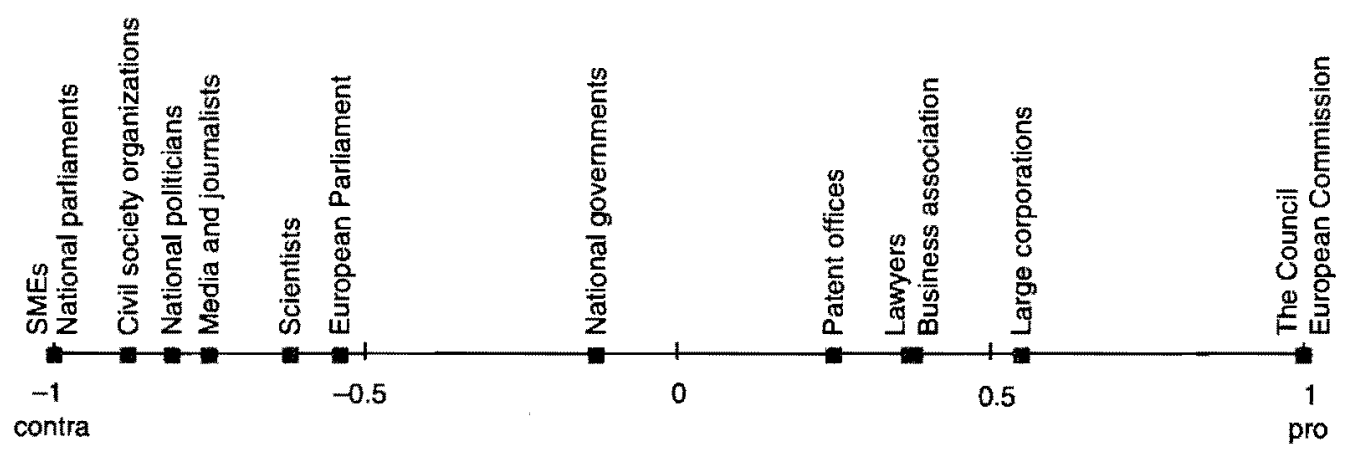

Note: Positions in this chart represent the mean positions of actors of the respective type. Scientists for example were in 1 instance reported to support the directive and 9 times reported to be against the directive and in 3 instances their position was neutral or ambivalent, resulting in an overall score of $-0.62\left(\left(1^{*} 1+9 *-1\right) / 13\right)$.

\section{Figure 6.2 Mean actor positions in the software patents conflict}

their status as experts in the field. Before this conflict, software patents were generally regarded as a highly specialized subfield of patent law. The fact that this became a politically contested issue is in itself a remarkable development.

The strong participation of SMEs is an important characteristic of the software patents conflict. The directive's opposition was mainly organized by computer programmers working self-employed or in SMEs. They successfully lobbied the European and national SME business associations, who in turn positioned themselves against the directive. The attempts of the European Information \& Communications Technology Industry Association (EICTA) and the Business Software Association (BSA) to mobilize SMEs in favor of the directive did not attract much press coverage. ${ }^{5}$ As we can see in Table 6.1, SMEs were the only relevant category of actors for which no claims were reported in favor of the directive. The only other actor groups that were unanimously either for or against the directive were a small number of national parliaments, who opposed it, and the Council, which supported it. Neither of these, however, was highlighted in reporting on the conflict. Of those actors who played a relevant role in the public discourse, not surprisingly, only the European Commission unequivocally supported the directive.

Figure 6.2, which plots the actor groups according to their overall position on the Software Patents Directive, shows that all of the other actor groups were split, although some were clearly more in favor of the directive than others. One large cluster of opponents scored between -1 and -0.5 on the positional scale, together representing a little over half ( 56 per cent) of the actors mentioned in the press. At the other end of the spectrum, the 
Table 6.2 Actors present in the enforcement conflict

\begin{tabular}{lccrrr}
\hline Actors & \multicolumn{2}{c}{ Reported Claims } & \multirow{2}{*}{ Pro } & \multirow{2}{*}{ Con } & \multirow{2}{*}{ Neutral } \\
\cline { 2 - 3 } & Percentage & Number & & & \\
\hline European Parliament & 29.2 & 14 & 9 & 5 & 0 \\
Civil society organization & 27.1 & 13 & 0 & 13 & 0 \\
Business association & 14.6 & 7 & 7 & 0 & 0 \\
European Commission & 8.3 & 4 & 4 & 0 & 0 \\
Big companies & 6.3 & 3 & 0 & 3 & 0 \\
Patent offices & 4.2 & 2 & 1 & 0 & 1 \\
National governments & 4.2 & 2 & 2 & 0 & 0 \\
Scientists & 4.2 & 2 & 0 & 2 & 0 \\
National politicians & 2.1 & 1 & 1 & 0 & 0 \\
Sum & $100^{*}$ & 48 & 24 & 23 & 1 \\
\hline
\end{tabular}

Note: * Error due to rounding.

Council, the Commission, lawyers, business associations, and a number of large individual firms supported the directive, but even the large firms were not unanimously in favor of it.

Looking only at single actors, rather than groups, the most important actor in the software patents conflict was clearly the FFII, which accounted for 5.8 per cent of all published claims. EICTA (4.0 per cent), Michel Rocard (3.6 per cent), Florian Müller ( 2.5 per cent), and Frits Bolkestein ( 2.5 per cent) were also noteworthy single actors who together were responsible for a little under one-fifth (18 per cent) of the claims. Interestingly, this constellation varied greatly from one country to the next. FFII was not mentioned at all in the French press but constituted 10 per cent of the claims in the German newspapers. Michel Rocard, on the other hand, was mentioned only once in Germany but accounted for 10 per cent of the claims in France. EICTA had an insignificant presence in both France and Germany, but was important in Poland and the UK, where it was responsible for 6.4 per cent and 10 per cent of the claims, respectively.

In the case of the IP Enforcement Directive the picture is more clear cut (see Table 6.2). Five actor groups dominated in the reporting: MEPs and political groups from the European Parliament, civil society organizations, business associations, the European Commission and three large corporations (British Telecom, Telecom Italia, and Nokia). Interestingly, in this case the large individual firms, all from the telecommunications sector, spoke out against the directive, whereas the business associations - in this case mainly from the music and information technologies industries - strongly supported the directive. However, ETNO, the business 


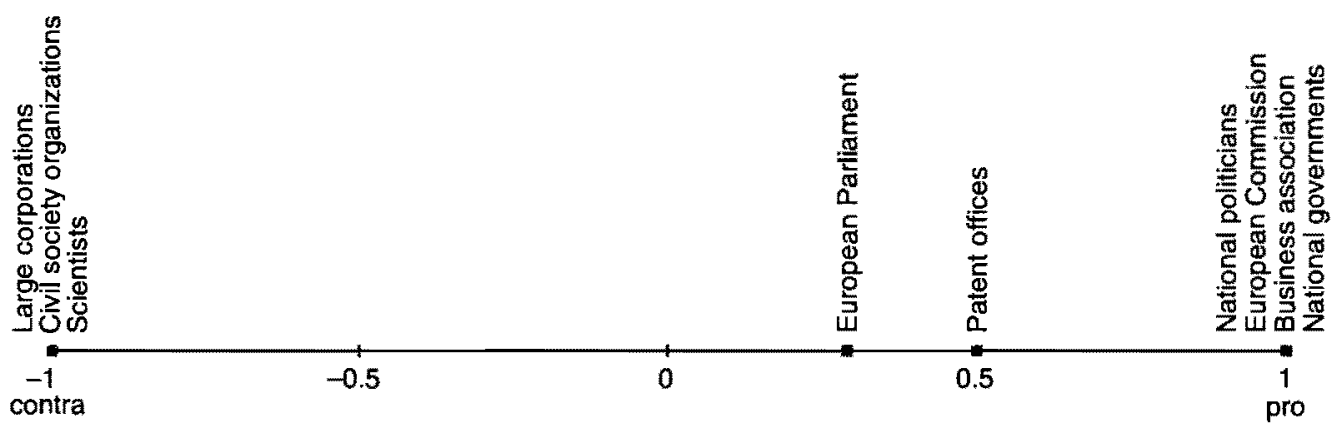

Figure 6.3 Mean actor positions in the IP enforcement conflict

association representing the telecommunications industry on the European level, was never mentioned in the newspapers, even though they actively tried to prevent the directive from being passed.

More so than in the software patents conflict, the actors were clustered largely at the extreme ends of the spectrum, with most actors - with the notable exception of the MEPs - either clearly for or clearly against the directive (see Figure 6.3). ${ }^{6}$

More than simply a measure of their respective influence in the debate, the relative frequency of each actor's appearance in the press also reflects their different strategies. The business associations and large corporations focused mainly on traditional lobbying channels. They tried to exert influence during the drafting and consultation phases of the process and later lobbied important MEPs. The civil society organizations, who were not able to use these avenues, concentrated their efforts much more on a public media strategy. Here again the media focused on the MEPs, who were as central to the decision-making process as the Council, but much more accessible.

Due to the lower number of claims in this conflict, a comparison between the four countries is less reliable than in the software patents case. In Poland the conflict was simply not covered in the press. We found only one article in which a claim concerning the Enforcement Directive was reported. This is not surprising, since the conflict ended before the EU enlargement, and therefore before Poland's entry into the EU. There was slightly more coverage of this conflict in the UK and French press than in Germany $(18,17$ and 11 claims, respectively), a sharp contrast to the situation in the software patents conflict, where the German press accounted for 123 of the total 277 claims, as compared with 56 in the UK, 55 in France, and 42 in Poland.

Based on this limited set of data, the most important actors in the IP enforcement conflict were the French MEP and rapporteur for the parliament Janelly Fourtou, commissioner Frits Bolkestein, the German MEP Angelika Niebler, the Foundation for Information Policy Research 
(FIPR), and IP Justice, who were each mentioned three times in the news. Again national differences were significant. Fourtou and Niebler were present only in their respective home countries. Bolkestein's claims were only reported in France, and the claims of the two non-governmental organizations (NGOs), FIPR and IP Justice, were only reported in the UK and Germany, respectively.

In both conflicts the actor constellation clearly reflected the degree to which the IP issue had been politicized. The actors involved in the conflicts represented not only business interests and legal experts but diverse stake-holders in civil society as well. FFII is an interesting case in itself. Its members are mainly individual software developers or CEOs of SMEs in the fields of software development and information technology. FFII claims to represent the business interests of its members and of IT SMEs in general, but it is not a business association in the traditional sense. In its internal structure and forms of action FFII more closely resembles an NGO. It is actually a hybrid between a business association and an NGO, which is also true for the LinuxPetition and the Economic Majority Campaign.

In the case of the IP Enforcement Directive, MEPs, commissioner Frits Bolkestein, and a few civil society organizations were the most important claims makers. Here one aspect is particularly interesting. The most important organizational actors on the proponents' side, IFPI (the International Federation of the Phonographic Industry) and the AntiPiracy Coalition, each appeared only once in the media discourse. Yet we know from interviews with key actors and from a network analysis of the two conflicts (Haunss and Kohlmorgen 2008b) that IFPI played an important role in drafting the Enforcement Directive proposal and had close ties with MEPs and members of the Commission. ${ }^{7}$ Its work was quite effective, but obviously IFPI relied on traditional forms of lobbying and more direct non-public avenues of interest representation to influence the decision-making process.

On the opponents' side, one important actor, ETNO (the European Telecommunications Network Operators Association), did not appear in the media, and from the European Digital Rights Initiative (EDRi), which our network analysis and expert interviews showed to be the central actor in the network of civil society organizations opposing the Enforcement Directive, only two claims were reported in the newspapers. This shows that EDRi was not very effective in placing claims in the media or in mobilizing actors.

\subsection{Framing}

Thus far we have concentrated on the characteristics of the actors involved in the two conflicts. We now take a closer look at the frames the actors 


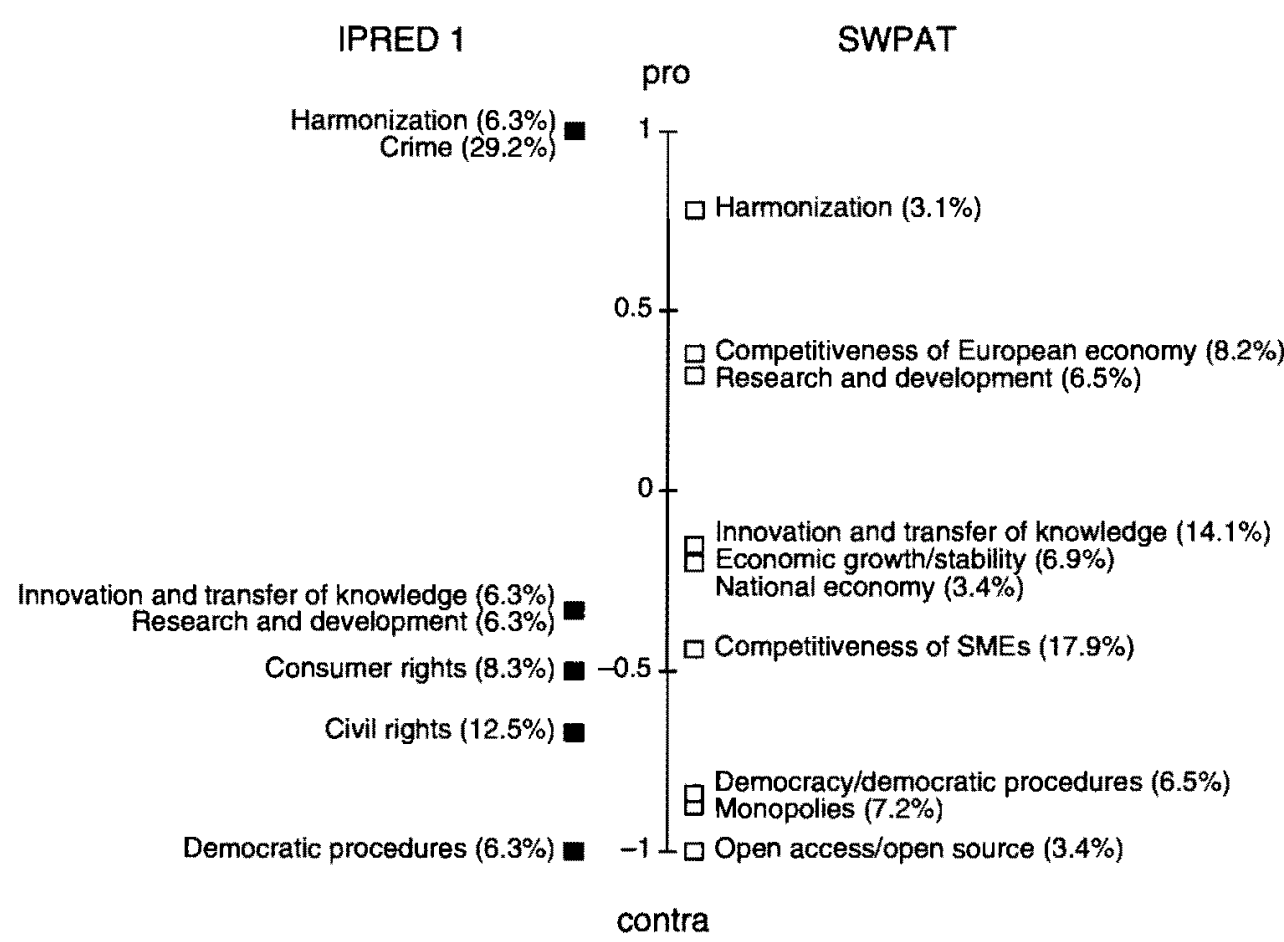

Note: Positions in this chart represent the mean positions of the frames. The research and development frame for example was used 6 times in a claim against the directive, 12 times in support and 1 time in a neutral or ambivalent form resulting in an overall score of 0.32 $\left(\left(6^{*}-1+12^{*} 1\right) / 19\right)$.

\section{Figure 6.4 Mean positions of frames in the two conflicts}

used to justify their claims. First it is important to note that in both conflicts roughly a third of the reported claims (SWPat: 31.4 per cent, IPRED 1: 29.8 per cent) contained no articulated frame, and in about 40 per cent of the claims more than one frame was reported. Overall we therefore have 291 reported claims containing articulated frames in the software patent conflict and 50 in the IP enforcement conflict. Again the picture is rather different in each case.

As Figure 6.4 shows, in the conflict around the IP Enforcement Directive, the dominant frame was the crime frame. It was used to justify 29.2 per cent of the claims and was the only frame used exclusively by the proponents of the directive. The criminality issue functions as a master frame that unites the diverse interests of the music and film industries, large software firms (especially Microsoft), and luxury goods manufacturers. In this frame the directive was about fighting product piracy and was necessary to protect consumers from counterfeit goods.

The opponents were not able to use this master frame in their own argumentation. Some of them tried to put forward the argument that 
IPRED 1 would criminalize ordinary citizens who only wanted to share their music with their friends. This can be interpreted as a kind of reversion of the crime frame. However, this criminalization frame did not appear as such in the public discourse. It was mostly subsumed under the frame of civil rights. And, to be precise, it is not a true re-framing, as it only objects to the severe penalties that would be attached to the prosecution of copyright and patent infringement. The foundation of the proponents' argument, that counterfeiting and product piracy entail high costs for companies and for entire economies, is a matter of empirical fact and therefore could not itself be refuted. One way to answer it would have been to argue that money spent prosecuting copyright infringers would make fewer resources available for prosecuting truly dangerous criminals. Instead of starting with the proponents' interpretation and re-framing it, however, the directive's opponents concentrated on constructing their own counter-frame, which focused on consumer and civil rights (used in 20.8 per cent of the claims). Unfortunately for them, these rights-based arguments were less successful than the piracy and counterfeiting frame used by the directive's proponents. As mentioned before, ETNO, the business association representing the telecommunication industry, did not appear as a public claims maker, preventing their main argument - that IPRED 1 would impose high costs on internet providers - from entering the public discourse about the directive. Nor did the arguments made by the automotive parts and generic medicines manufacturers play any role in the debate. The only frame that was exclusively used by opponents of the directive was the democratic procedures frame, which was mainly used by MEPs criticizing the selection of the rapporteur. ${ }^{8}$

It is striking that in the IP enforcement conflict the frame "culture" does not show up in the reporting, especially since IFPI, the interest group representing the music industry, was the main actor in the conflict. A number of participants we interviewed told us that, in their perception, the argument that the directive would protect (European) culture and artists played a significant role in shaping the conflict. Be that as it may, this framing obviously did not resonate in the public discourse.

Overall the opponents did not succeed in creating a common interpretive frame, and consequently were not able to agree on a common political strategy. Without a master frame that resonated with the public, the opponents were unable to construct a collective actor with a more or less consistent identity. The frames of the two relevant opponent networks (CSOs and telcos) remained disconnected and neither frame on its own was able to convince the general public or the majority of the decision makers. This is one reason for the opponents' failure to defeat the Enforcement Directive. 
The positional distribution of frames in the software patents conflict gives a rather different picture from that in the IP enforcement conflict. Figure 6.4 shows that the frames various actors used were generally much more contested than in the other conflict, indicating a much more vibrant public debate. Unlike in the IP enforcement conflict, where arguments basically coexisted independently, in the software patents conflict opponents engaged directly with the other side's arguments and tried to reframe them according to their aims. Looking at the seven most frequently used frames, which together comprise almost two-thirds of the frames, one can see that the conflict was primarily cast as an economic issue. In Figure 6.4 the democratic procedures frame is the only one that does not refer to the economy.

Competitiveness of SMEs was used in 17.9 per cent of the claims. Both opponents and supporters of the directive used this frame (contra: 36; neural: 3, pro: 13), with opponents (software developers, SMEs, and some MEPs) claiming that the directive would endanger European SMEs, who would lack the knowledge and resources to use the patent system to their advantage, and supporters (large firms, European and national business associations, and again some MEPs) arguing that SMEs would profit from the directive, as patented "computer implemented inventions" would attract venture capital. The importance of the SME argument over the course of the conflict is well illustrated by the mobilization in the last phase of the conflict in which EICTA mobilized 56 SMEs to speak out in support of the directive. Our interviews confirm that until that point, neither the Commission nor the directive's other supporters had taken the SMEs seriously.

The second most frequently used frame in the software patents conflict depicts it as an issue of innovation and the transfer of knowledge (14.1 per cent). Again this was a highly disputed frame, used by both sides (contra: 23, neutral: 1, pro: 17) to support their claims. The opponents of the directive usually combined this frame with the SME frame, arguing that SMEs are the cornerstone of innovation in Europe, and that by putting SMEs at a disadvantage software patents would have a negative impact on European innovation. The other side generally followed the conventional wisdom of the economic and legal mainstream, which saw strong IP protection and especially patent protection as necessary for the protection of investments in innovation. According to this argument, not being able to file patents for computer implemented inventions would keep large corporations from investing in Europe, which would negatively affect not only individual firms but the whole European economy and result in the loss of many jobs. Thus, the competitiveness of SMEs and innovation frames were clarified and invigorated by both camps, though they were 
interpreted differently. This is a special case of "frame amplification" (Snow et al. 1986).

The only relevant ${ }^{9}$ frame that was used exclusively by one side only in the software patents conflict was the open access/open source frame, which was an attempt by some of the directive's opponents to construct a counter-frame similar to those used in the IP enforcement conflict. This open source frame - the argument that open source software should generally be preferred to closed source proprietary software - was relevant to some degree in the internal discussions among opponent organizations, ${ }^{10}$ but in the conflict as a whole the argument too closely mirrored the interests of those opposing the directive to incorporate the interests of the other side. It also played only a minimal role in the public discourse. ${ }^{11}$

Two other frames, the monopolies and the democracy frames, were also almost exclusively used by the opponents. MEPs made use of the democracy frame when, after the Parliament's first reading of the directive, the Commission and later on the Council completely ignored the Parliament's amendments, and when subsequently several presidencies in the Council, specifically Ireland, the Netherlands, and finally Luxembourg, tried to pass the directive without discussion. The relative strength of the democracy frame ( 6.5 per cent) illustrates the fact that one level of the conflict was an institutional power struggle between Council, Commission, and Parliament, in which the Parliament tried to defend its newly augmented decision-making rights in the co-decision procedure. The democracy frame, which was powerful primarily in the final phase of the conflict between March and July of 2005, helps to explain the reluctance of some MEPs to let the common position of the Council pass in the second reading - even if some of them did not object to the patentability of computer implemented inventions. The democracy frame was not related to the issue of software patents initially. It developed as a legitimacy frame in response to the decision-making process and was then combined with frames that were originally derived from the software patent issue. This is an example of "frame bridging", a process that describes the linkage of two structurally disconnected frames (Snow et al. 1986).

The research and development frame, on the other hand, was used primarily by supporters of the directive, who argued that patents would be necessary to recover the research and development costs involved in inventing the product. The directive's opponents picked up on this frame, however, and claimed that software patents would in fact inhibit research, because they would make sequential innovation, a dominant practice in the field of software engineering, more difficult and more costly.

The opponents were successful in re-framing the issue of software 
patents, which was originally framed by the European Commission as a harmonization, European competitiveness, and innovation issue. Over the course of the conflict, these initial frames were overtaken by the frames competitiveness of SMEs and innovation and transfer of knowledge. Specifically, the innovation frame, which was originally used by the Commission and large corporations, was re-interpreted by FFII and others to make the case that innovation is in fact largely promoted by SMEs and individual software developers, and would therefore be jeopardized rather than enhanced if the Software Patents Directive were adopted.

\section{CONCLUSION}

This analysis has revealed the publicly visible claims-making processes surrounding two recent European conflicts over intellectual property rights. One striking difference between these conflicts is that the software patents conflict took place mainly in the public sphere, whereas the one about the Enforcement Directive was largely a lobbying conflict. This publicity was an important factor for the actors opposing the Software Patent Directive - who were the weaker side of the conflict in terms of their access to resources - allowing them to influence the decision-making process and pursue their interests successfully.

Moreover, our analysis illustrates on two levels the importance of how an issue is framed:

1. At the level of interaction within the network of actors mobilizing on the same side of an issue, collective action frames are necessary to develop a coherent interpretation and a coordinated action strategy to create a collective actor with a coherent collective identity.

2. In the public sphere the resonance of a frame determines its potential to become hegemonic and influence those decision-makers that depend on public opinion - in the two cases presented here, this was mainly the MEPs.

In the case of the Enforcement Directive the proponents managed to construct a hegemonic master frame. They claimed that the directive was about "fighting against criminality and product piracy", and this master frame was accepted by the majority of the actors involved as an appropriate interpretation. Consequently, the directive was seen as the proper tool to solve the problem of product piracy. Even some of the left-wing MEPs accepted this frame and the problem solving strategy it implied.

On the other hand, the opponents of the Enforcement Directive were 
unable to reconcile the frames of the two primary groups of actors into a coherent oppositional master frame that could accommodate the various interests opposing the directive. Instead each group advanced its own counter-frame, interpreting the conflict as a consumer issue, a civil rights issue, an issue of access to information, and so on. But none of these frames on its own was able to counter the hegemonic frame from the other side of the discursive field. While the argument made by civil society organizations - that the Enforcement Directive would threaten civil rights and adversely affect innocent citizens - had at least some traction with a number of MEPs, the critique leveled by the telecommunications firms and generics manufacturers was not taken up by other actors and never played more than a minor role in the public debate. IPRED 1 was a clear case of a failed counter-framing strategy. The directive's opponents were not able to re-frame the dominant crime frame, nor did any of the opponents' attempts to establish a counter-frame succeed.

In contrast, the conflict over the Software Patents Directive is a good example of a successful re-framing strategy. Rather than concentrating their efforts on constructing a consistent counter-frame, the opponents of this directive successfully shifted the original frames used by the Commission (innovation, harmonization, and European competitiveness), effectively turning them on their head. To do this, the opponents reaffirmed the necessity of innovation and a competitive European economy, but claimed that the principal agents of innovation in the European IT sector are SMEs and that only a directive that effectively prevents software patenting would safeguard innovation. The trajectory of this conflict was a discursive struggle in which both sides continuously tried to re-frame this innovation frame to include their respective core interests. Both actor groups engaged in attempts with frame bridging and frame amplification, but attempts to construct genuine counter-frames remained marginal.

In the software patents conflict, rather than a struggle to establish a hegemonic frame, we see attempts to knit various frames together to shift the frame's overall meaning. We suggest calling this strategy frame bundling. It tries to alter the meaning of an original frame by bundling it with other frames that change the content of the whole package. In this case the opponents tied a bundle that contained the frames innovation and transfer of knowledge, economic growth and stability, growth of national economies, and competitiveness of SMEs. The result was that the innovation and transfer of knowledge frame that was originally used to argue in favor of the directive now became an argument against software patents and, subsequently, against the directive. The opponents' master frame - that innovation depended on the competitiveness of SMEs, which could only be secured without software patents - provided a unified collective action 
perspective, which allowed them to mobilize a diverse constituency. Along with the democracy frame, it resonated in the broader SME sector, and more importantly, with many MEPs, who finally stopped the directive.

The political claims analysis of the two IP conflicts supports our argument that the framing of the issue profoundly affects the outcomes of the decision-making process. It adds to the literature on framing by showing that under certain conditions re-framing strategies may be more successful than counter-framing strategies. With only two cases we are not able to fully specify these conditions. Nonetheless, our findings suggest that a number of key factors are important:

1. Embeddability Re-framing is likely to be more effective if the issue being framed can be linked up with some larger conflict over normative values. The dominant frame can then be recast in a way that taps into popular moral sentiments around the larger conflict, for example, the provision of health services versus property rights.

2. Ease of redefinition A re-framing strategy is more likely to succeed if the dominant frame lends itself to reformulation; that is, if it can be easily reappropriated and does not automatically lock one into a static set of associations. For example, innovation is generally considered a good thing and crime a bad thing, but there are more "sellable" notions about how to foster innovation than there are about how to deal with crime. Once something is framed as a crime, it is very difficult to dislodge that idea (whether by saying "no, it's not a crime" or by saying "this isn't about crime"), and opposing the directive becomes associated with being "soft on crime" or pro-criminal.

3. Actor diversity The more diverse the interests are within a coalition, the more difficult it is to establish a counter-frame as a unifying master frame. A gradual re-framing strategy may be more successful in such a situation.

While further research is needed before we can conclusively determine the conditions under which different framing strategies allow weak actors to successfully influence public discourse, the above propositions may offer a good place to start.

Last but not least, our research also demonstrates the limits of the political claims approach. A network analysis of the two conflicts (see Haunss and Kohlmorgen 2008b) reveals that the complete network of participating actors is much larger than the group we were able to identify by analyzing newspaper reports. Some actors who obviously have played important roles in the two conflicts were completely absent in the press. While a political claims analysis based on newspaper data can reveal the 
public part of a political conflict, it also obscures other routes actors use to influence decision-making processes. We have demonstrated the importance of framing for shaping public discourse and influencing political processes. Only by combining this approach with other methods will we be able to generate an accurate picture of the conflicts and more complete understanding of the determinants of political influence.

\section{NOTES}

1. The research for this article was made possible through a research grant from the FritzThyssen Foundation.

2. However, there is one significant difference in the de facto decision-making process: in the case of IPRED 1 , the decision-making process was considerably accelerated through the introduction of a so-called "trialogue", that is, informal negotiations between the European Parliament, the European Commission, and the Council of the European Union. The main actors involved in this legislative procedure wanted an adoption at the first reading of the directive, before the EU enlargement in May 2004. There were concerns that the new EU member states (some of which were facing widespread IPR infringement) might complicate and delay the deliberations.

3. According to a former Commission employee, even the Commission circulated its preparatory documents with filenames containing "swpat".

4. According to some European parliamentarians, this controversy generated one of the most intensive political conflicts the European institutions have seen in the recent past (Michel Rocard, interviewed by Sebastian Haunss, 17 January 2007, interview 9, transcript).

5. In June 2005, 56 SMEs published an "SME Manifesto on Patents for Computerimplemented Inventions" (http://w3.cantos.com/05/eicta-504-0arfg/documents/SME_ manifesto_0106.pdf). The Manifesto does not mention EICTA, but the website where it is available to be signed is run by EICTA and its member firms, all of whom are large IT firms (http://w3.cantos.com/05/eicta-504-0arfg/cii.php?page=aboutus).

6. The UK patent office is not shown among the supporters only because one of the two articles in which it appeared reported a rather ambivalent claim.

7. Yolanda Smits, interviewed by Sebastian Haunss and Lars Kohlmorgen, 12 December 2006 , interview 2 , transcript.

8. Their main point of criticism was that French MEP Janelly Fourtou's private interests as the wife of Jean-René Fourtou, the then CEO of Vivendi-Universal, would interfere with her role as rapporteur for the directive.

9. We classified as "relevant" all frames that were used in at least 3 per cent of the claims.

10. Thomas Eimer (2007) distinguishes two different conceptual approaches within the opponents' camp on how to treat software: where the FFII favors a "club good" or "open source" approach, which guarantees some rights for the developer, other relevant organizations, such as the Free Software Foundation (FSF), champion the idea of free software as a public or common good. This latter approach extends the largely economic perspective of the club good approach and takes a political position that is more fundamentally critical of capitalism and neoliberalism. This difference, however, did not play an important role in the campaign.

11. It is quite interesting that the European Commission chose not to use the open source/ open access frame, as it would have fitted nicely with the argumentation it made in the March 2004 anti-competition case in which the Commission ordered Microsoft to pay $€ 497$ million for failing to disclose the interface information necessary for other firms to integrate their media player software into the Windows desktop environment - a classic open access case. 


\section{REFERENCES}

Benford, Robert D. and David A. Snow (2000), 'Framing Processes and Social Movements: An Overview and Assessment', Annual Review of Sociology 26(1), 611-39.

Bouwen, Pieter (2002), 'Corporate Lobbying in the European Union: the Logic of Access', Journal of European Public Policy 9(3), 365-90.

COM (2002), Proposal for a Directive of the European Parliament and of the Council on the patentability of computer-implemented inventions, Brussels: Commission of the European Communities.

COM (2003), Proposal for a Directive of the European Parliament and of the Council on measures and procedures to ensure the enforcement of intellectual property rights, Brussels: Commission of the European Communities.

Drahos, Peter and John Braithwaite (2003), Information Feudalism. Who Owns the Knowledge Economy?, New York: New Press.

Eimer, Thomas R. (2007), 'Zwischen Allmende und Clubgut - Der Einfluss von Free/Open Source Akteuren in der Europäischen Union', Hagen: Fernuniversität Hagen.

G8 (2007), Chair's summary. Heiligendamm, 8 June, http://www.g-8.de/nn_220074/ Content/EN/Artikel/_g8-summit/anlagen/chairs-summary.html.

Gamson, William A., Bruce Fireman and Steven Rytina (eds) (1982), Encounters with Unjust Authority, Homewood, Illinois: Dorsey Press.

Gerhards, Jürgen and Dieter Rucht (1992), 'Mesomobilization: Organizing and Framing in Two Protest Campaigns in West Germany', American Journal of Sociology 98(3), 555 96.

Gorlin, Jacques (1985), 'A Trade Based Approach for the International Copyright Protection for Computer Software', unpublished, on file with author.

Greenwood, Justin (1997), Representing Interests in the European Union, Basingstoke: Macmillan.

Haunss, Sebastian and Lars Kohlmorgen (2008a), Codebook for the Analysis of Political Claims in Conflicts on Intellectual Property Rights in Europe, http:// www.ipgovernance.eu/publications/IPGovCodebook.pdf.

Haunss, Sebastian and Lars Kohlmorgen (2008b), 'Conflicts About Intellectual Property Claims: The Role and Function of Collective Action Networks', IPGovernance Working Paper No. 1, http://ssrn.com/paper=1162209.

Hein, Wolfgang (2007), 'Global Health Governance and WTO/TRIPS: Conflicts Between "Global Market-Creation" and "Global Social Rights", in Wolfgang Hein, Sonja Bartsch and Lars Kohlmorgen (eds), Global Health Governance and the Fight Against HIV/AIDS, Basingstoke: Palgrave Macmillan, pp. 38-66.

Hein, Wolfgang and Lars Kohlmorgen (2008), 'Global Health Governance: Conflicts on Global Social Rights', Global Social Policy 8(1), 80-108.

Koopmans, Ruud (2002), Codebook for the Analysis of Political Mobilisation and Communication in European Public Spheres, http://europub.wz-berlin.de/Data/ Codebooks per cent20questionnaires/D2-1-claims-codebook.pdf.

Koopmans, Ruud and Paul Statham (1999), 'Political Claims Analysis: Integrating Protest Event and Political Discourse Approaches', Mobilization 4(2), 203-22.

Meier, Henk Erik (2005), 'Wissen als geistiges Privateigentum? Die Einfriedung der Public Domain', Leviathan 33(4), 492-521. 
Richardson, Jeremy (2000), 'Government, Interest Groups and Policy Change', Political Studies 48(5), 1006-25.

Sell, Susan K. (2003), Private Power, Public Law. The Globalization of Intellectual Property Rights, Cambridge: Cambridge University Press.

Snow, David A. (2004), 'Framing Processes, Ideology, and Discursive Fields', in David A. Snow, Sarah Anne Soule and Hanspeter Kriesi (eds), The Blackwell Companion to Social Movements, Oxford: Blackwell, pp. 380-412.

Snow, David A. and Robert D. Benford (1992), 'Master Frames and Cycles of Protest', in Adlon D. Morris and Carol McClurg Mueller (eds), Frontiers in Social Movement Theory, New Haven, CT: Yale University, pp. 133-55.

Snow, David A., Burke E. Rochford Jr, Steven K. Worden and Robert D. Benford (1986), 'Frame Alignment Processes, Micromobilization and Movement Participation', American Sociological Review 51(4), 464-81. 